\title{
A myofunctional approach to treatment of anterior cross bites
}

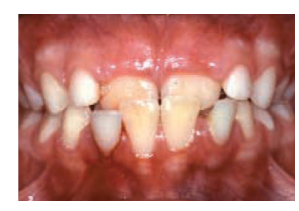

\author{
Philippe AMAT
}

The tongue is a tiny organ andyet it can glorify itself to perform great things! See how a tiny fire can engulf an entire forest in flames: the tongue is also a fire.

SAINT JAMES

Extract of Epistles, III, 5.

\section{ABSTRACT}

A cross bite of one or more anterior teeth can interfere with the function of the incisocanine block in guiding mandibular escursive and protrusive movements out of a position of occlusion.

When this type of malocclusion occurs without any associated skeletal imbalance, orthodontists can correct it with relative ease by using a variety of well-documented appliances. The objective of this article is to describe a myofunctional approach for dealing with this problem.

In it, the orthodontist first removes the cross bite's blockage of tooth movement by placing glass-ionomer cement blocks on the occlusal surfaces of posterior teeth. When this is done the tongue, labial, and cheek musculature can accomplish their role, without inhibition, of correcting positions of the dentoalveolar arches in two or three months.

\section{KEYWORDS}

Cross bite

Anterior guidance

Myofunctional treatment

Occlusion build-ups

Therapeutic education.

Address for correspondence:

P. AMAT,

19 place des Comtes

du Maine,

72000 Le Mans.

amatph@noos.fr 


\section{1 - INTRODUCTION}

The action of anterior teeth in guiding mandibular movements out of occlusion seems to be the most appropriate means of regulating this activity both mechanically and physiologically ${ }^{21}$.

But a cross bite of one more anterior teeth can interfere with this action and should be corrected promptly.

Such treatment allowing young patients to once more masticate properly thanks to the restoration of anterior guidance will greatly improve the chances of achieving optimum facial development especially of the antero-lateral sectors of the maxillae ${ }^{10}$ because the tongue will again be able to exert positive force against the palatal vault and the occlusal forces generated by the incisocanine sectors of the dental arches will again function properly.

When this type of malocclusion occurs without any associated skeletal imbalance, orthodontists can correct it with relative ease by choosing a therapeutic device from a variety of well-documented appliances $2,7,13,19,20$ whose number is as vast as the ingenuity of the clinician.

The objective of this article is to present another approach that is not mechanical but myofunctional for achieving this correction.

\section{2 - TREATMENT OF ANTERIOR CROSS BITES}

\section{2 - 1 - The virtuous triangle of dento-facial orthopedics}

It is appropriate to remember that the therapeutic objectives of dentofacial orthopedics can be categorized in the form of a virtuous triangle of dento-facial orthopedics ${ }^{3}$ (fig. 1):

- to remove or control the etiological factors;

- to make the structural framework as well balanced as possible;

- to establish or reestablish proper function.

Accomplishment of each element of this triad of objectives contributes to achievement of the others and none can be considered concluded until all three have been completed.

\section{2 - 2 - The myofunctional approach}

The alveolar processes develop at an interface where the exocentric pressures exerted by the tongue are balanced by the band of the lip and cheek muscles. Any tooth that has drifted into a place distant from this interface will, in the absence of obstacles, be forced back toward that point of equilibrium by the nearest muscle group. A good example of this is the spontaneous alignment of the anterior sector of the mandibular dental arch that occurs after the loss of an over-retained temporary incisor that we have all observed clinically (fig. $7 \mathrm{~b}$ and 8 b). 


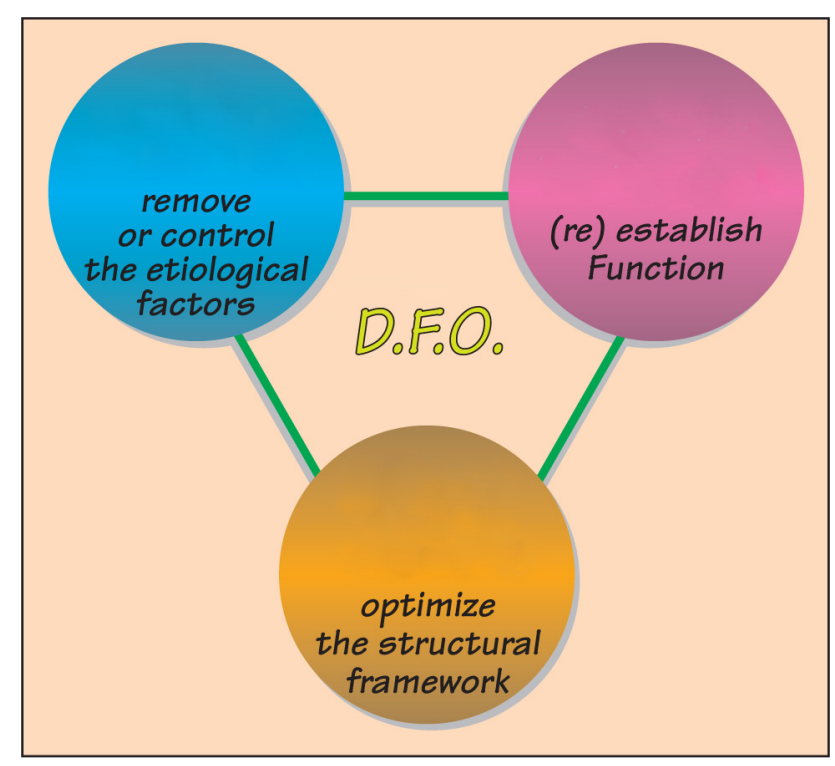

Figure 1

The virtuous triangle of dento-facial orthopedics3.

In the case of an anterior cross bite not associated with a skeletal deformity the first step in optimizing the structural framework (fig. 1) is for the dentist to free the occlusion by placing posterior bite blocks.

Muscular forces will promote spontaneous movement of the affected dental elements to the desired positions in two to three months.

\section{2 - 3 - The myofunctional approach used clinically}

A number of methods for freeing the occlusion such as anterior bite planes $^{11}$ or occlusal blocks ${ }^{1,19}$ have been proposed for treatment of anterior cross bites. Also applicable are plates with indirect planes as well as the direct paths of posterior composite additions ${ }^{15,16}$ which, with selective grinding, are the methods used in Neuro-Occlusal Rehabilita- tion $^{14}$ (NRO), a technique for reconstituting the masticatory system and optimizing the stimuli that are indispensable for harmonious development of the stomatognathic apparatus. We prefer bite blocks of ionomer-glass cement for freeing the occlusion. Biocompatible and capable of increasing caries resistance by its liberation of flouride ${ }^{8,12}$, this material allows us to create bite blocks that cause patients little discomfort or inconvenience because they interfere minimally with speaking and mastication and are also easy to remove after completion of treatment. We place them on second temporary molars or first permanent molars, asking patients to bite down lightly before the cement has set so that the occlusal contact on right and left sides will be roughly equal, thus greatly decreasing the need for us to remove high spots. in case their should be a fracture of part or all of these bite blocks before 


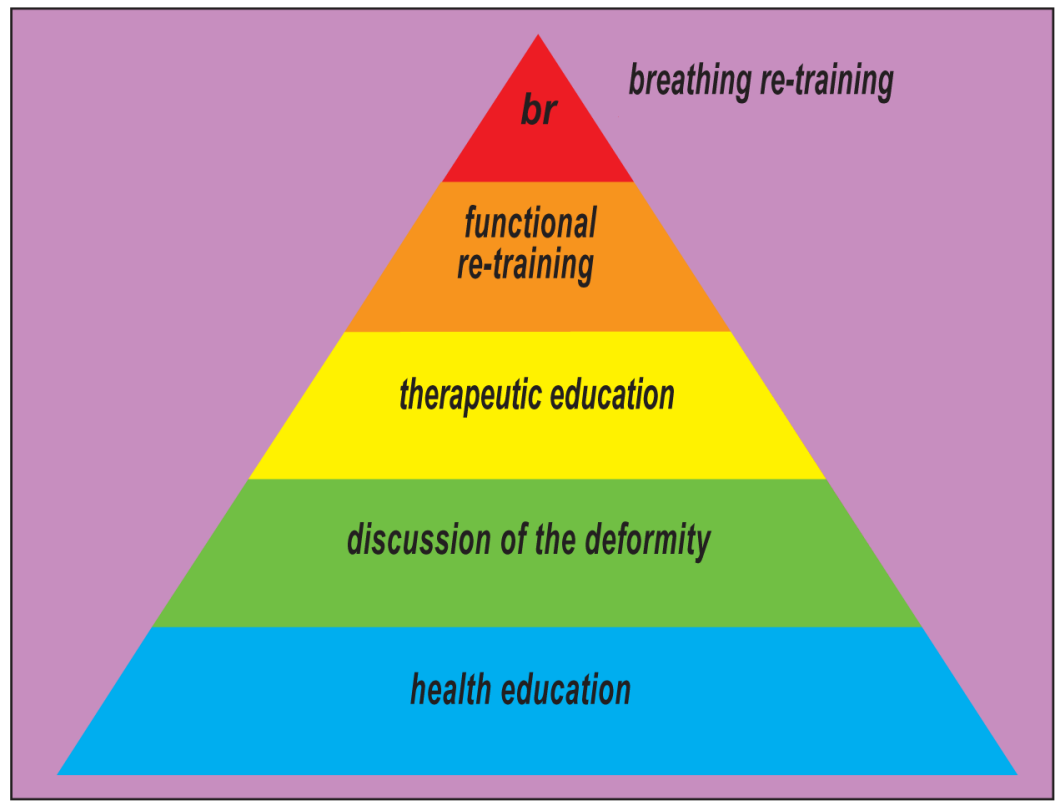

Figure 2

Education for patients in dento-facial orthopedics.

conclusion of therapy, replacing or repairing them with additional glassionomer cement is a relatively simple task.

After several days of getting used to them, our patients find these bite blocks quite acceptable. After placing them we see our patients at six week intervals. The action of these posterior bite blocks allow the tongue, lip, and cheek musculature to fully exercise their role of shaping the dental arches and, after several months, this action succeeds in correcting the initial anterior cross bite.

We find that after we remove the posterior blocks, some patients a slight open bite. That reflects the partial intrusion of the posterior teeth that supported them. But this disappears in a few weeks.
Most patients find this simple myofunctional therapeutic approach bothers them only slightly and, in many cases, not at all. Later, in the course in the didactory phase of therapy, (fig. 2), patients can learn how to reestablish optimal functioning of all oral activities, another objective of dento-facial orthopedics (fig. 1). If need be, orthopedic treatment adapted to specific features of the oro-facial complex, eventually, in some cases, associated with surgical correction of anatomical obstacles as well as medical treatment of respiratory allergies will be able to contribute to achievement of correct nasal breathing at rest ${ }^{17}$, of proper cervico-cephalic posture ${ }^{5}$, and to a global improvement of facial morphogenesis ${ }^{6,18}$. 


\section{3 - CLINICAL CASES}

\section{3 - 1 - Clinical case $n^{\circ} 1$}

Margaux, a 6 year, 7 month old girl, presented with a cross bite of her anterior teeth (fig. 3 a to c).

We placed glass-ionomer cement occlusal blocks on the occlusal surfaces of her maxillary second temporary molars (fig. 4 a to $\mathrm{c}$ ) and in three months the cross bite had disappeared allowing us to remove them (fig. 5 a to c).

\section{3 - 2 - Clinical case $n^{\circ} 2$}

Fanny, an 8 year, 9 month old girl came to us with an anterior guidance disrupted by the cross bite of her

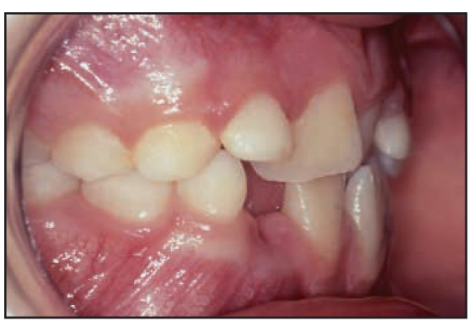

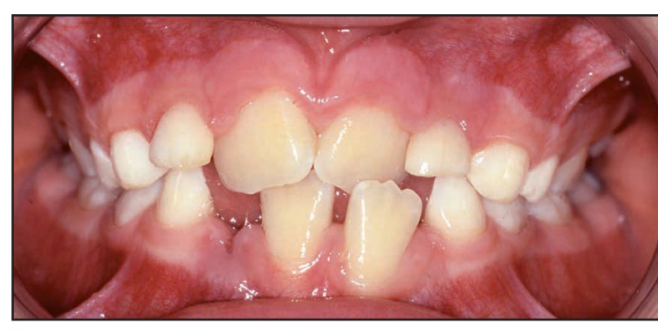

b

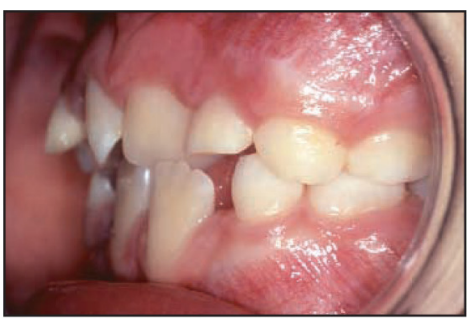

Figures 3 a to $c$

Clinical case 1. Six year, 7 month old girl, with a pre-treatment cross bite of the upper left lateral.

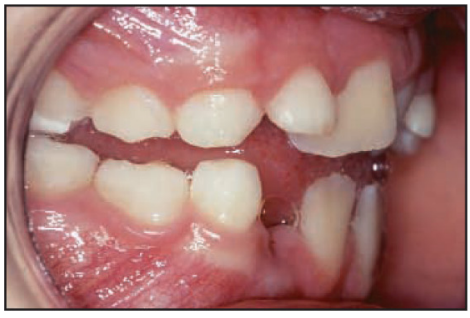

a

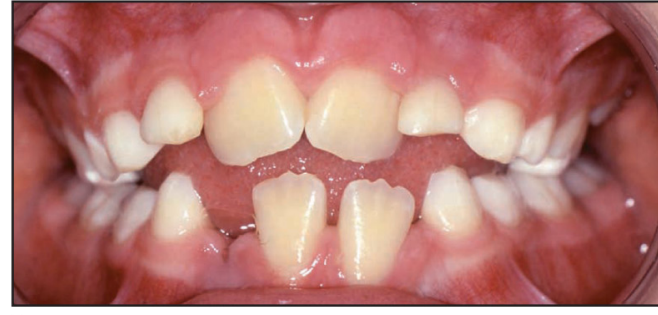

b

Figures 4 a to $c$

Bite freeing occlusal build-ups of glass-ionomer cement placed on the temporary maxillary second molars.

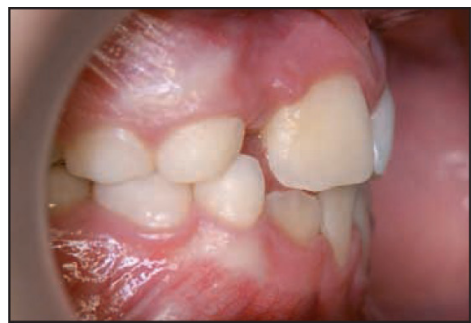

a

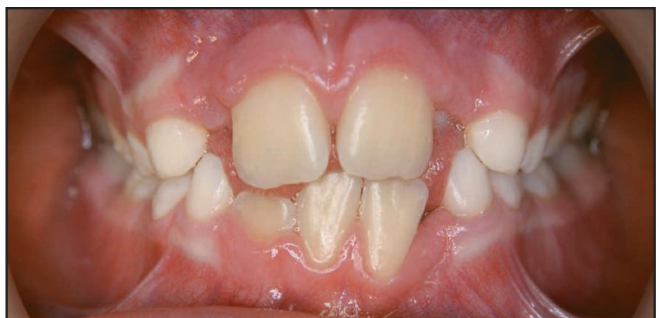

b

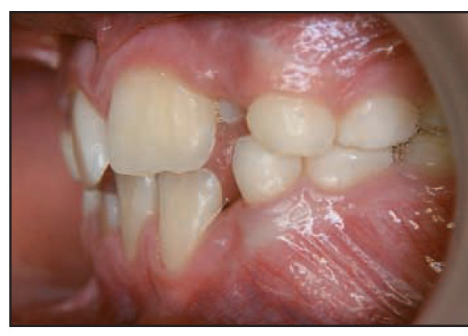

Figures 5 a to $c$

The occlusion three months after myofunctional treatment. 


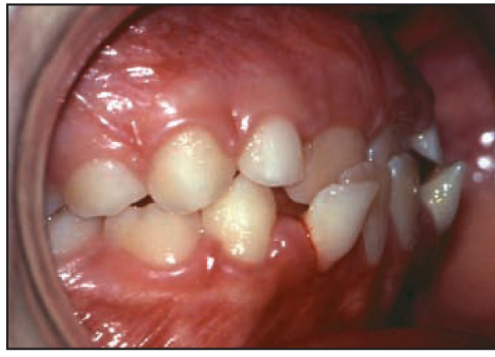

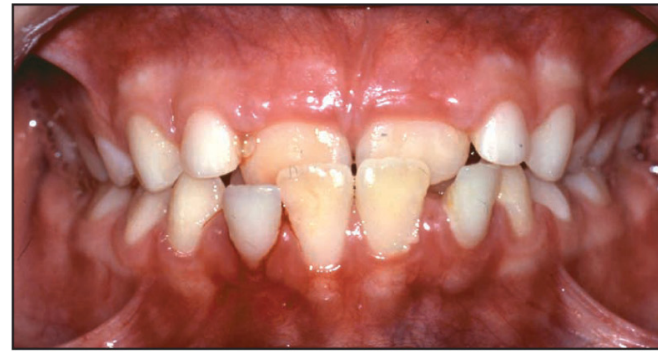

b

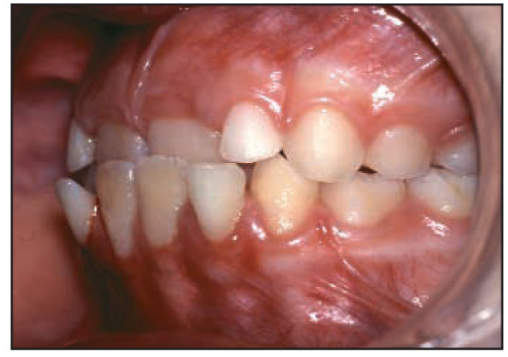

Figures 6 a to $c$

Clinical case 2. Eight year, 9 month old girl with a cross bite of the upper central incisors before treatment.
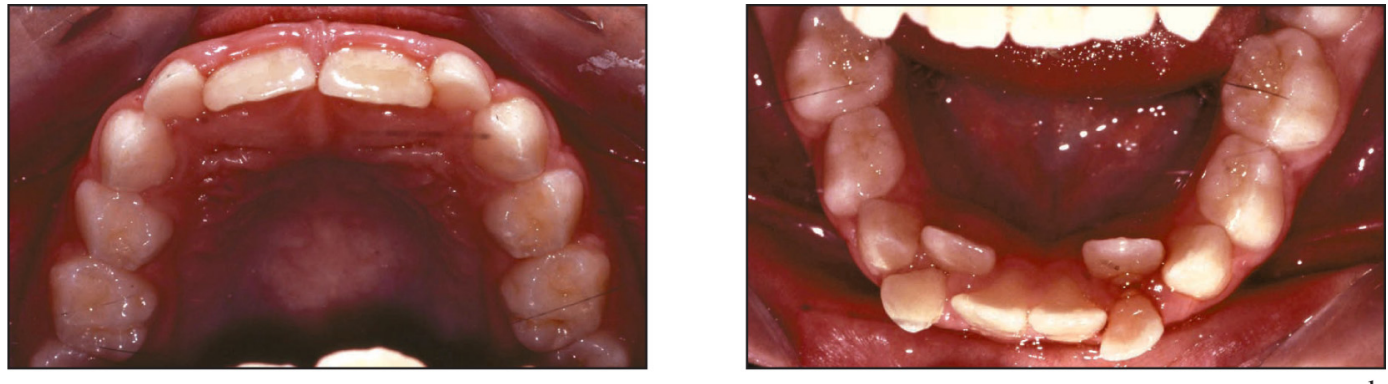

Fiqures $7 a$ and $b$

Occlusal views of the dental arches. The lower lateral incisors have erupted in an ectopic lingual position.

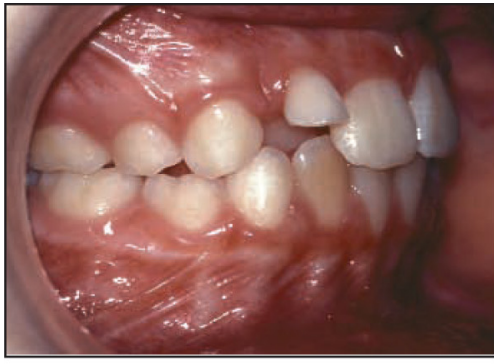

a

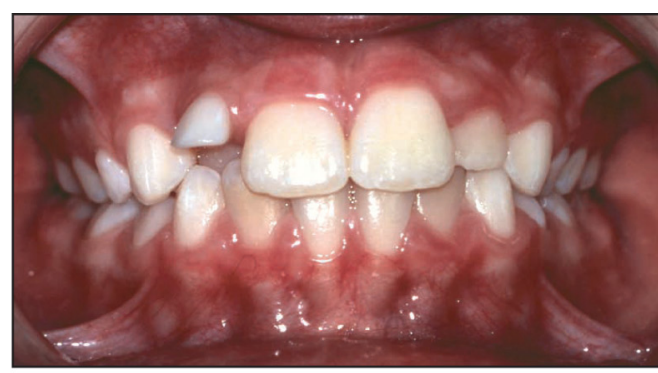

b

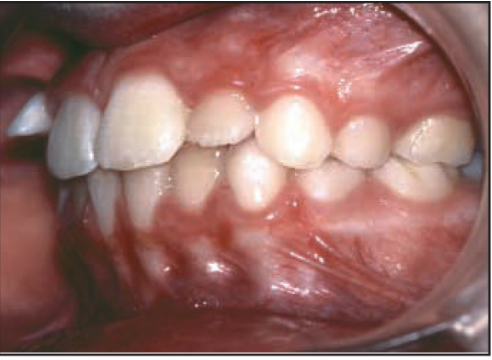

C

Fiqures 8 a and $c$

Intra-oral views, one year after correction of the cross bite of the upper central incisors. Because of the over-retention of a temporary incisor the upper right lateral incisor has erupted in lingual cross bite.

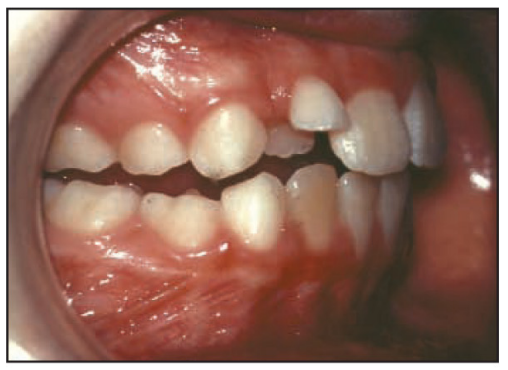

a

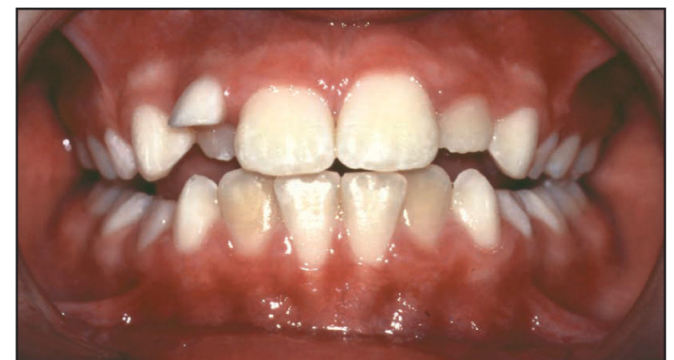

b

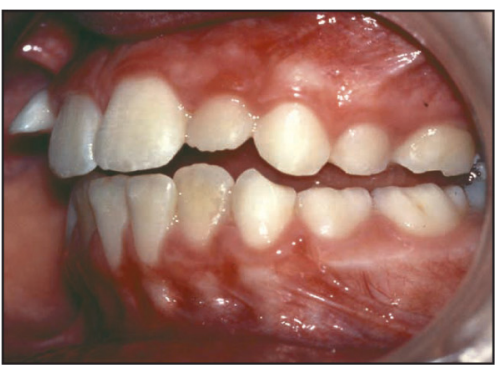

$\mathrm{c}$

Fiqures 9 a and $c$

Two occlusal bite blocks were placed on the biting surfaces of the temporary mandibular first molars. 


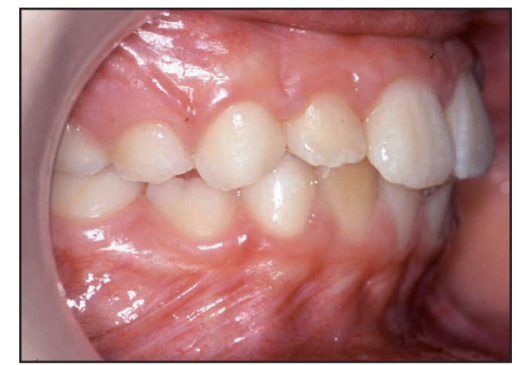

a
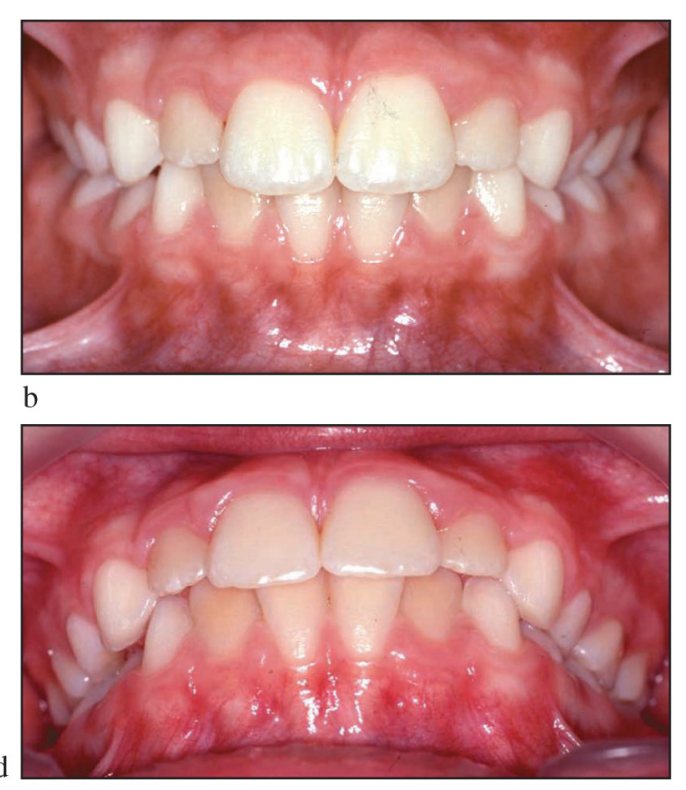

Fiqures 10 and $d$

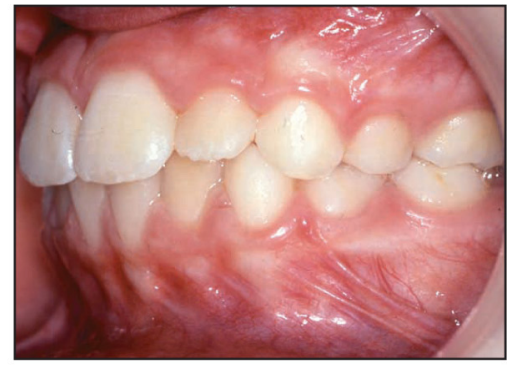

c

Three months later, a functional anterior guidance has been testord.

upper central incisors (fig. 6 a to c), (fig. $7 \mathrm{a}$ and b). The mandibular lateral incisors had erupted in an ectopic lingual position because of the continued presence in the arch of their temporary predecessors (fig. 7 b).

After correction of the anterior cross bite, Fanny did not return for a checkup visit for a full year at which time we observed a new cross bite of the upper right lateral incisor because of the presence of an over-retained temporary incisor (fig. 8 a to c). On the other hand, the shedding of two lower temporary incisors had been followed by a spontaneous alignment of the permanent mandibular anterior teeth (fig. 8 b).

We eliminated any occlusal interference by placing two posterior cement bite blocks on the biting surfaces of the first mandibular molars (fig. 9 a to c) and at the same time extracting tooth 52 .
Three months later a functional anterior guidance had been restored (fig. 10 a to d).

\section{3 - 3 - Clinical case $n^{\circ} 3$}

Louise, a twelve year old girl, wanted her orthodontic treatment to be limited to correction of the cross bite of the left maxillary canine (fig. 11 a to c), (fig. 12 a and b). and was unwilling to wear either fixed or removable appliances. She did consent to myofunctional therapy accompanied by placement of two bite blocks on the occlusal surfaces of the first maxillary molars (fig. 13 a to $\mathrm{c}$ ).

The cross bite was corrected in two months (fig. 14 a to c).

Six months later, when we suggested it was time to undertake treatment of her Class II Division 2 


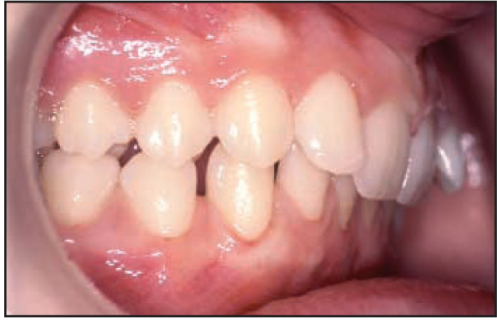

a

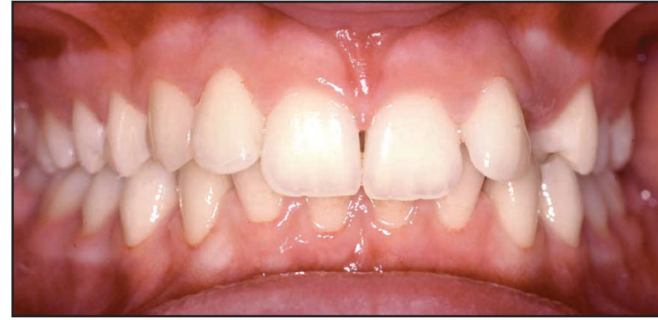

b

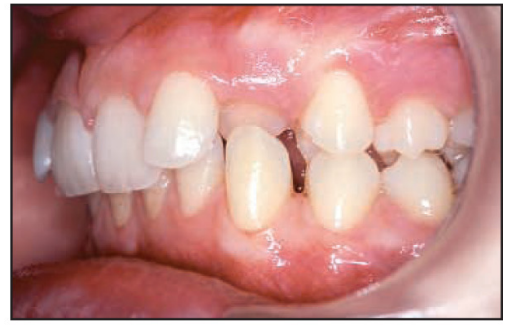

$\mathrm{c}$

Figures 11 a to $C$.

Clinical case 3. A 12 year old girl with a cross bite of the upper left canine.
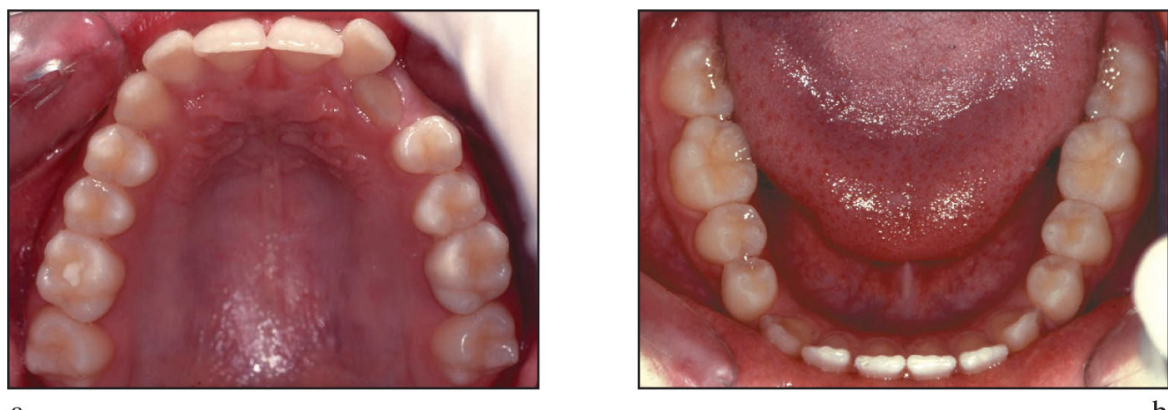

Fiqures 12 and $b$

Occlusal views of the dental arches. The upper left canine has erupted in an ectopic lingual position.

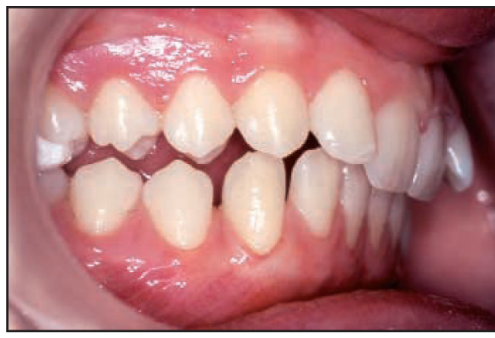

a

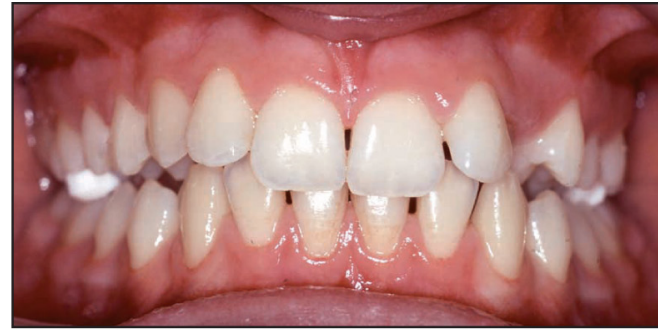

b

Figures 13 a to $c$

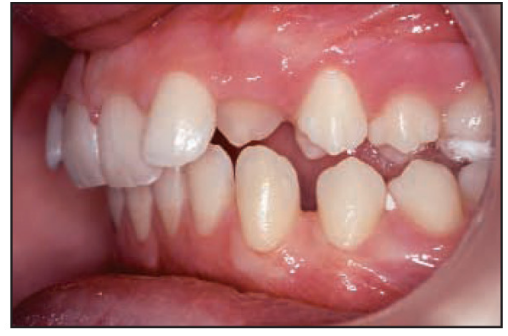

Placement of two bite-blocks on the occlusal surfaces of temporary maxillary first molars.

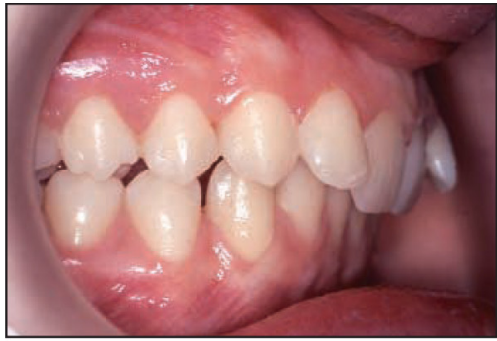

a

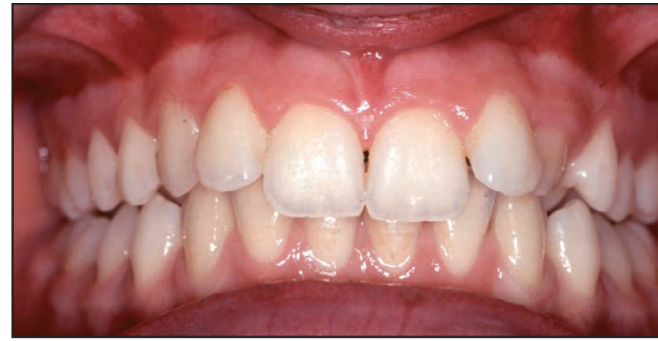

Fiqures 14 a and $c$

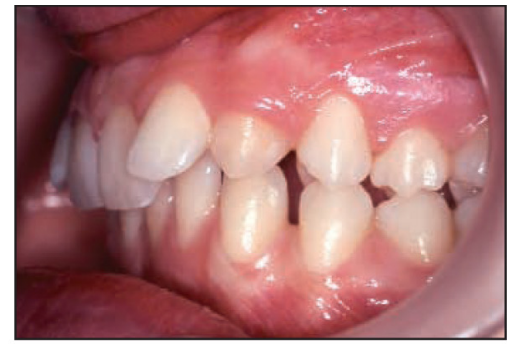

The cross bite of the upper left canine has been corrected in two months. 


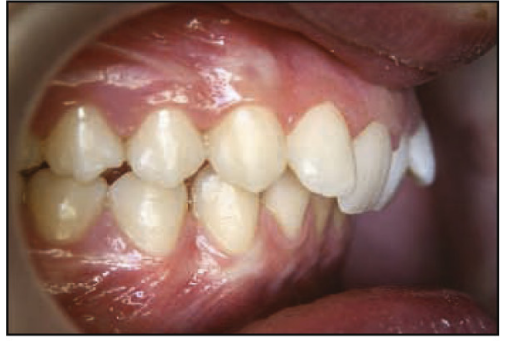

a

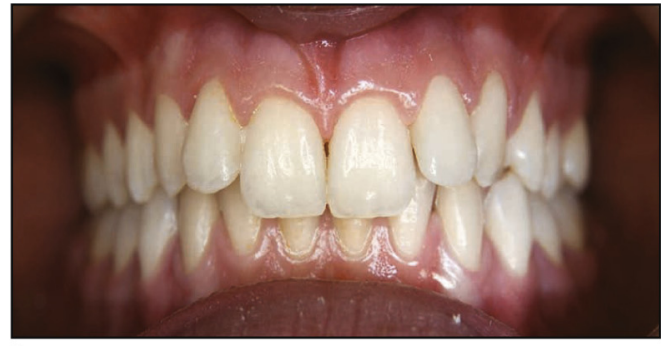

b

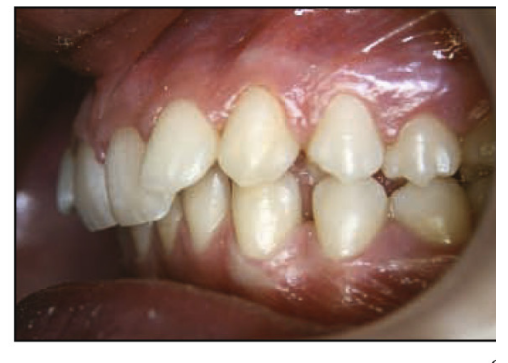

Figures 15 a to $\mathrm{C}$.

Six months later, the position of the upper left canine has continued to improve.

malocclusion, she again refused therapy, satisfied with the appearance of her upper canine tooth whose position was continuing to improve spontaneously (fig. 15 a to c).

\section{4 - CONCLUSION}

In conformance with evidence based dentofacial orthopédics ${ }^{4}$ practitioners are urged not to limit their proposals for treatment to those techniques they are accustomed to using. In this connection they should con- sider using the myofunctional approach to treatment of anterior cross bites, which is a simple and effective means of restoring anterior functional guidance for patients.

\section{REFERENCES}

1. Aknin JJ, Gebeile S. La thérapeutique du "Distal active concept» appliquée á la denture mixte : une étude comparative. Orthod Fr 2001;72:355-73.

2. Amat $P$. Intérêt du rétablissement précoce du guide antérieur par l'emploi d'une gouttière fonctionnelle et orthopédique. $18^{\mathrm{es}}$ Journées Internationales du Collège National d'Occlusodontologie 2001.

3. Amat P. Apport d'une gouttière fonctionnelle et orthopédique au traitement des malocclusions de classe II. Orthod Fr 2003;74:71-81.

4. Amat P. What would you choose: evidence-based treatment or an exciting, risky alternative? Am J Orthod Dentofacial Orthop 2007;132:724-25.

5. Amat P. Occlusion, orthodontics and posture: are there evidences? The example of scoliosis. J Stomat Occ Med 2009;2:2-10.

6. Amat P, Talmant J. Ventilation, orthopédie dento-faciale et santé : I'aval de la HAS. Rev Orthop Dento Faciale 2009;43:3-4.

7. Amat P. Clinical application of the Essix III Corrector. J Clin Orthod. Accepté pour publication.

8. Cacciafesta V, Sfondrini MF, Tagliani P, Klersy C. In Vitro fluoride release rates from orthodontic bonding adhesives. Am J Orthod Dentofacial Orthop 2007;132:656-62. 
9. Croll TP, Lieberman WH. Bonded compomer slope for anterior tooth crossbite correction. Pediatr Dent 1999;21:293-4.

10. Delaire J. Maxillary development revisited : relevance to the orthopaedic treatment of Class III malocclusions. Eur J Orthod 1997,19:289-311.

11. Jeanmonod A. Le plan de morsure rétro-incisif. Cah Prothèse 1982;37:91-105.

12. Lavernhe $P$, Lodter $C$, Sharrock $P$, Grégoire G. Biocompatibilité des colles orthodontiques: I'apport des ciments aux verres ionomères. Rev Orthop Dento Faciale 2000;34:539-54.

13. Marquet F. Corriger une occlusion incisive inversée. Rev Orthop Dento-Faciale 2007;41:219-20.

14. Planas P. Réhabilitation Neuro-Occlusale Rno. Paris : CDP, 2006.

15. Ramirez-Yañez GO. Planas Direct Tracks for Early Crossbite Correction. J Clin Orthod 2003;6:294-8.

16. Simoes WA. Selective grinding and Planas direct tracks as a source of prevention, J Pedod 1981;5: 298-314.

17. Talmant J, Deniaud J. Ventilation nasale et récidive. Orthod Fr 2000;71:127-41.

18. Talmant J, Talmant JC, Deniaud J, Amat P. Du traitement étiologique des AOS. Rev Orthop Dento Faciale 2009;43:3-4.

19. Tzatzakis V, Gidarakou I. Correction of anterior crossbite using occlusal build-ups. J Clin Orthod 2007;41:393-7.

20. Vadiakas G, Viazis AD. Anterior crossbite correction in the early deciduous dentition. Am J Orthod Dentofacial Orthop 1992;102:160-2.

21. Valentin C, El Hamid A, Dowek D, Yakhou O. Les objectifs de l'équilibration occlusale. Réalités Cliniques 1990;1:279-301. 